\title{
Evaluation of specific humoral immune response in pigs vaccinated with cell culture adapted classical swine fever vaccine
}

\author{
Mrinal K. Nath ${ }^{1}$, D. K. Sarma², B. C. Das ${ }^{1}$, P. Deka ${ }^{3}$, D. Kalita ${ }^{4}$, J. B. Dutta ${ }^{1}$, G. Mahato ${ }^{1}$, S. Sarma ${ }^{5}$ and P. Roychoudhury
}

1. Department of Veterinary Epidemiology and Preventive Medicine, College of Veterinary Science, Assam Agricultural University, Khanapara, Guwahati, Assam, India; 2. ICAR-National Research Centre on Pig, Rani, Guwahati, Assam, India

3. Department of Veterinary Microbiology, College of Veterinary Science, Assam Agricultural University, Khanapara,

Guwahati, Assam, India; 4. ICAR - All India Co-ordinated Research Project on Pigs, College of Veterinary Science,

Assam Agricultural University, Khanapara, Guwahati, Assam, India; 5. Department of Veterinary Bio-chemistry, College of Veterinary Science, Assam Agricultural University, Khanapara, Guwahati, Assam, India; 6. Department of Veterinary Microbiology, College of Veterinary Science and Animal Husbandry, Central Agricultural University, Aizawal, Mizoram, India.

Corresponding author: Mrinal K. Nath, e-mail: mrinalnath2007@yahoo.com, DKS: dksarma1956@gmail.com,BCD: bipban.das@gmail.com,PD: drpankajaau@gmail.com, DK: dhireswar64@gmail.com,JBD: duttajyotib@gmail.com, GM: gaurangamahato@yahoo.com, SS: sarmasatya49@yahoo.com,PR: parimal74@rediffmail.com

Received: 28-12-2015, Revised: 27-01-2016, Accepted: 02-02-2016, Published online: 25-03-2016

doi: 10.14202/vetworld.2016.308-312 How to cite this article: Nath MK, Sarma DK, Das BC, Deka P, Kalita D, Dutta JB, Mahato G, Sarma S, Roychoudhury P (2016) Evaluation of specific humoral immune response in pigs vaccinated with cell culture adapted classical swine fever vaccine, Veterinary World, 9(3): 308-312.

\begin{abstract}
Aim: To determine an efficient vaccination schedule on the basis of the humoral immune response of cell culture adapted live classical swine fever virus (CSFV) vaccinated pigs and maternally derived antibody (MDA) in piglets of vaccinated sows.

Materials and Methods: A cell culture adapted live CSFV vaccine was subjected to different vaccination schedule in the present study. Serum samples were collected before vaccination (day 0) and 7, 14, 28, 42, 56, 180, 194, 208, 270,284 and 298 days after vaccination and were analyzed by liquid phase blocking enzyme-linked immunosorbent assay. Moreover, MDA titre was detected in the serum of piglets at 21 and 42 days of age after farrowing of the vaccinated sows.

Results: On 28 days after vaccination, serum samples of $83.33 \%$ vaccinated pigs showed the desirable level of antibody titer $\left(\log _{10} 1.50\right.$ at $1: 32$ dilution), whereas $100 \%$ animals showed $\log _{10} 1.50$ at $1: 32$ dilution after 42 days of vaccination. Animals received a booster dose at 28 and 180 days post vaccination showed stable high-level antibody titre till the end of the study period. Further, piglets born from pigs vaccinated 1 month after conception showed the desirable level of MDA up to 42 days of age.

Conclusion: CSF causes major losses in pig industry. Lapinised vaccines against CSFV are used routinely in endemic countries. In the present study, a cell culture adapted live attenuated vaccine has been evaluated. Based on the level of humoral immune response of vaccinated pigs and MDA titer in piglets born from immunized sows, it may be concluded that the more effective vaccination schedule for prevention of CSF is primary vaccination at 2 months of age followed by booster vaccination at 28 and 180 days post primary vaccination and at 1 month of gestation.
\end{abstract}

Keywords: antibody titer, classical swine fever vaccine, liquid phase blocking-enzyme-linked immunosorbent assay, pig.

\section{Introduction}

Classical swine fever (CSF) is a highly contagious viral disease of domestic and wild swine caused by genus Pestivirus of family Flaviviridae. The disease is considered as a major factor of economic losses to the swine industry and pig farming community [1-3].

Although E2 subunit marker vaccines have been developed in different countries for control of CSF [4], lapinized vaccines are still being used in

Copyright: Nath, et al. Open Access. This article is distributed under the terms of the Creative Commons Attribution 4.0 International License (http://creativecommons.org/licenses/by/4.0/), which permits unrestricted use, distribution, and reproduction in any medium, provided you give appropriate credit to the original author(s) and the source, provide a link to the Creative Commons license, and indicate if changes were made. The Creative Commons Public Domain Dedication waiver (http://creativecommons.org/ publicdomain/zero/1.0/) applies to the data made available in this article, unless otherwise stated. many countries including India [5]. However, many outbreaks of the disease in vaccinated pig herd have been reported in India including North Eastern region [6]. Besides, lapinized vaccine doses being produced in India is not sufficient to immunize even $1 \%$ of the total pig population of the country. Thus, cell culture system will be more realistic to produce adequate doses of classical swine fever vaccines for the development of the pig industry in India. Cell culture attenuated CSF vaccine is also safe and produce a good level of immunity similar to the freeze dried lapinized vaccine. Besides in cell culture system, it is easy to determine the virus concentration [7].

Therefore, the present study was proposed to evaluate the kinetics of humoral immune response in cell culture adapted CSF vaccinated pigs as well as maternally derived antibody (MDA) of their offspring using different vaccination schedule. 


\section{Materials and Methods}

\section{Ethical approval}

Ethical approval for the study was obtained from Institutional Animal ethics Committee of College of Veterinary Science, Assam Agricultural University, Khanapara.

\section{Vaccine}

A live attenuated cell culture adapted vaccine ( $10^{3}$ tissue culture infective dose $50 \%$ per dose) developed by ICAR-National Fellow Project, Department of Microbiology, College of Veterinary Science, Assam Agricultural University, Khanapara, was used in the present study. The lapinised $\mathrm{C}$ strain of CSF virus (CSFV) was adapted in PK-15 cell line and after extensive field trials conducted by ICAR-National Fellow Project, the cell culture adapted $\mathrm{C}$ starin of the virus was found to be safe for immunization.

\section{Experimental animal}

Twenty four CSF crossbred female piglets of 2 months old reared at ICAR - All India Coordinated Research Project on Pig, Assam Agricultural University, Khanapara were used for the present study. As per approval from the Institutional Animal Ethics Committee, all the animals were maintained under uniform dietary and managerial regime of the farm, and the experimental piglets were divided into four groups (Group A to D) comprising of six piglets in each group. Each group was kept isolated and supplied with separate feeding and watering troughs. Deworming of all the experimental animals were done prior to the commencement of the experiment. Further, before commencement of the experiment, serum samples of all the piglets were evaluated to ascertain that they are seronegative to CSFV and subjected to the following vaccination schedule by intramuscular route:

\begin{tabular}{|c|c|c|c|c|}
\hline \multirow[t]{2}{*}{ Groups } & \multicolumn{4}{|c|}{ Vaccination schedule } \\
\hline & $\begin{array}{l}2^{\text {nd }} \text { month } \\
\text { of age }\end{array}$ & $28 \mathrm{dpv}$ & $180 \mathrm{dpv}$ & $\begin{array}{l}1 \text { month of } \\
\text { gestation }\end{array}$ \\
\hline Group A & $\begin{array}{l}\text { Primary } \\
\text { vaccination }\end{array}$ & NV & $\begin{array}{l}1^{\text {st }} \\
\text { booster }\end{array}$ & NV \\
\hline Group B & $\begin{array}{l}\text { Primary } \\
\text { vaccination }\end{array}$ & $\begin{array}{l}1^{\text {st }} \\
\text { booster }\end{array}$ & $\begin{array}{l}2^{\text {nd }} \\
\text { booster }\end{array}$ & NV \\
\hline Group C & $\begin{array}{l}\text { Primary } \\
\text { vaccination }\end{array}$ & $\begin{array}{l}1^{\text {st }} \\
\text { booster }\end{array}$ & $\begin{array}{l}2^{\text {nd }} \\
\text { booster }\end{array}$ & 3rd booster \\
\hline Group D & $\begin{array}{l}\text { Unvaccinated } \\
\text { control group }\end{array}$ & & & \\
\hline
\end{tabular}

$\mathrm{NV}=$ Not vaccinated, $\mathrm{dpv}=$ Days post vaccination

\section{Serum samples and antibody detection}

Serum samples were collected before vaccination (0 day) and 7, 14, 28, 42, 56, 180, 194, 208, 270, 284 and 298 days post vaccination (dpv) to monitor the humoral immune response of the experimental animals. In general, vaccination against CSF has routinely been performing at 6-month interval; therefore in the present study booster vaccination was attempted at $180 \mathrm{dpv}$. Further, to study the MDA titre, serum samples were collected from the piglets at 21 and 42 days of age born from vaccinated sows. To determine specific antibody level of the vaccinated herd as well as piglets born, in house liquid phase blocking (LPB) - enzyme-linked immunosorbent assay (ELISA) developed by the ICAR-National Fellow Project, Assam Agricultural University, Khanapara was performed according to the standard protocol with slight modification [8]. The percent inhibition in each well was calculated in relation to the respective antigen control using the formula given below, and the reciprocal of the serum dilution corresponding to $50 \%$ inhibition was considered as titer.

Percent inhibition $=\frac{\text { OD of test well }- \text { Background OD }}{\text { OD of antigen control }- \text { Background OD }}$

\section{Results}

The percentages of animals showing LPBELISA antibody titre minimum of $\log _{10} 1.50$ (1:32) against CSFV in different $\mathrm{dpv}$ are shown in Table-1. On the day of vaccination, none of the animals in any group showed antibody titre in serum samples. Out of six animals in each groups, one animal (16.67\%) of group A and B and two animals (33.33\%) of group C possessed $\log _{10} 1.50(1: 32)$ antibody titre on $14 \mathrm{dpv}$. Serum samples tested at $28 \mathrm{dpv}$ revealed an increase in the numbers of animals showing such antibody titre (83.33\% in all the groups). At $42 \mathrm{dpv}$, the antibody titre increased further and all animals in the vaccinated groups showed desired antibody level despite that animals of Group B and C received a booster dose on 28 dpv. All the animals within these groups were found to have maintained a stable antibody titre upto $56 \mathrm{dpv}$. Serum samples tested at $180 \mathrm{dpv}$ revealed a decline in numbers of animals showing $\log _{10} 1.50$ (1:32) antibody titre. None of the animals of group $\mathrm{A}$ showed the desired titre on $180 \mathrm{dpv}$ but the numbers of animals possessing $\log _{10} 1.50(1: 32)$ antibody titre were five $(83.33 \%)$ and four $(66.67 \%)$ in Group B and C, respectively. Following revaccination on $180 \mathrm{dpv}$, the serum samples of $100 \%$ animals were found to possess desired LPB-ELISA antibody titre on 194, 208, 270, 284 and $298 \mathrm{dpv}$ for all the groups. However, animals of Group $\mathrm{C}$ were again vaccinated during gestation after 1 month of conception (around $270 \mathrm{dpv}$ ). After farrowing piglets born from the sows of different Groups A, $\mathrm{B}, \mathrm{C}$ and D were also tested by LPB-ELISA for detecting MDA at different periods of time (Table-2). Piglets born from all the sows of Group A, B and C were carrying the MDA to their offsprings. On 21 day of their age, one piglet in Group A (17.0\%), five in group B $(83.0 \%)$ and six numbers in Group C $(100.0 \%)$ had a detectable level of MDA by LPB-ELISA. Further, none of the piglets in Group A, one piglet in Group B $(17.0 \%)$ and four piglets in Group $C(66.66 \%)$ were recorded to have MDA at 42 days of age. In the present 
Table-1: Percentage of pigs possessing LPB-ELISA antibody titre $\log _{10} 1.50(1: 32)$ against CSFV in different groups at different dpv.

\begin{tabular}{lccccccccccc}
\hline Group & $\begin{array}{l}\mathbf{0} \text { and } \\
\mathbf{7} \text { day }\end{array}$ & $\begin{array}{c}\mathbf{1 4} \\
\mathbf{d p v}\end{array}$ & $\begin{array}{c}\mathbf{2 8} \\
\mathbf{d p v}\end{array}$ & $\begin{array}{c}\mathbf{4 2} \\
\mathbf{d p v}\end{array}$ & $\begin{array}{c}\mathbf{5 6} \\
\mathbf{d p v}\end{array}$ & $\begin{array}{c}\mathbf{1 8 0} \\
\mathbf{d p v}\end{array}$ & $\begin{array}{c}\mathbf{1 9 4} \\
\mathbf{d p v}\end{array}$ & $\begin{array}{c}\mathbf{2 0 8} \\
\mathbf{d p v}\end{array}$ & $\begin{array}{c}\mathbf{2 7 0} \\
\mathbf{d p v}\end{array}$ & $\begin{array}{c}\mathbf{2 8 4} \\
\mathbf{d p v}\end{array}$ & $\begin{array}{c}\mathbf{2 9 8} \\
\mathbf{d p v}\end{array}$ \\
\hline $\mathrm{A}$ & 0.00 & 16.67 & 83.33 & 100.00 & 100.00 & 0.00 & 100.00 & 100.00 & 100.00 & 100.00 & 100.00 \\
$\mathrm{~B}$ & 0.00 & 16.67 & 83.33 & 100.00 & 100.00 & 83.33 & 100.00 & 100.00 & 100.00 & 100.00 & 100.00 \\
$\mathrm{C}$ & 0.00 & 33.33 & 83.33 & 100.00 & 100.00 & 66.67 & 100.00 & 100.00 & 100.00 & 100.00 & 100.00 \\
$\mathrm{D}$ & 0.00 & 0.00 & 0.00 & 0.00 & 0.00 & 0.00 & 0.00 & 0.00 & 0.00 & 0.00 & 0.00 \\
\hline
\end{tabular}

LPB-ELISA=Liquid phase blocking - enzyme-linked immunosorbent assay, CSFV=Classical swine fever virus, dpv=Days post vaccination

Table-2: Percentage of piglets born from immune sows possessing LPB-ELISA antibody titre $\log _{10} 1.50(1: 32)$ against CSFV in different groups at different age (days).

\begin{tabular}{lcc}
\hline Groups & 21 days & 42 days \\
\hline A & 16.67 & 0.00 \\
$B$ & 83.33 & 16.67 \\
C & 100.00 & 66.66 \\
$D$ & 0.00 & 0.00 \\
\hline
\end{tabular}

LPB-ELISA=Liquid phase blocking - enzyme-linked immunosorbent assay, CSFV=Classical swine fever virus

study, none of the piglets of Group D showed MDA even at 21 days of their age.

\section{Discussion}

In India, pork meat production is the fastest growing segment of the livestock sector. However, CSF is endemic in India and causes huge losses to both the pork industry and backyard farmers. A study in 2011 study estimated the losses caused by CSF in India are around 2 billions INR [9]. Like many endemic countries, the control policy for CSF in India depends on vaccination against the disease to reduce or avoid serious economic losses.

The internationally accepted methods for the detection of antibody response after vaccination are virus neutralization test (VNT), LPB-ELISA and solid phase competition ELISA [10]. In the present study, LPB-ELISA was standardized and used for antigenic characterization of CSFV isolates and compared the result with neutralization peroxidase linked assay (NPLA) and both the tests showed positive correlation [8]. On serological study of antibodies to foot and mouth disease virus, it is reported that 1:16 of VNT was equivalent to 1:32 by LPB-ELISA [11]. The LPBELISA is known to have a high correlation with serum neutralization test and could efficiently evaluate the potency of commercial vaccines $[12,13]$. Thus, antibody titre $\log _{10} 1.50$ (1:32) was considered as protective antibody titre to evaluate the potency of the presently used cell culture adapted CSF vaccine. All the animals included in the experiment were tested before vaccination and were found to be free from any detectable level of antibody titre in serum against CSFV. The result of LPB-ELISA revealed a gradual rise of antibody titre in all the three cell culture adapted CSFV vaccinated groups of animals (Figure-1). On $28 \mathrm{dpv}$, $83.33 \%$ animals of each vaccinated groups maintained the protective antibody titre and it further increased to

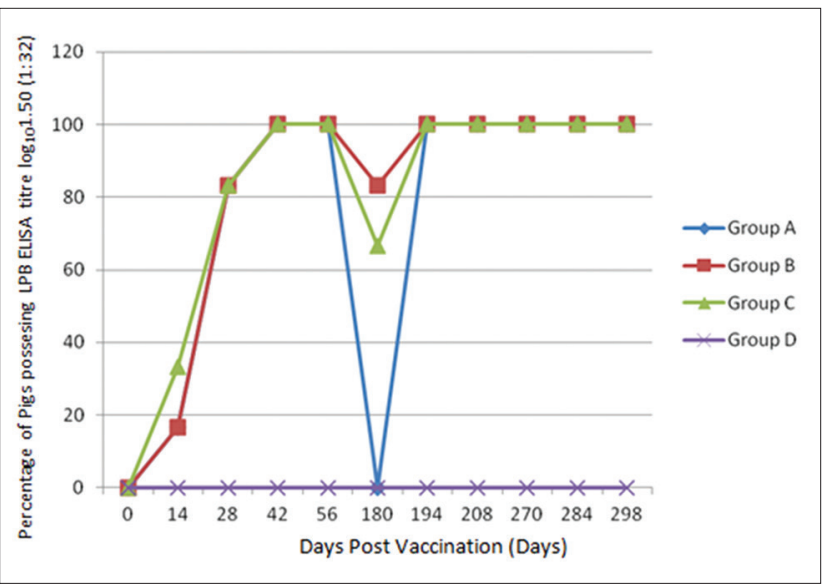

Figure-1: Percentage of pigs possessing liquid phase blocking - enzyme-linked immunosorbent assay antibody titre $\log _{10} 1.50(1: 32)$ against classical swine fever virus in different groups at different days post vaccination.

$100 \%$ on $42 \mathrm{dpv}$ and maintained this peak till $56 \mathrm{dpv}$. This pattern of protective antibody titre indicated that sufficient humoral antibodies conferred a stable protection to all animals which might be due to the high efficacy and a possibility of cell culture adapted CSF vaccine virus replication in host cells. Similar observation was also reported where the neutralizing antibodies could not be detected till 14 dpv by NPLA when pigs were vaccinated with $\mathrm{C}$ strain vaccine through intramuscular route, but the antibody titre increased 28 $\mathrm{dpv}$ and reached maximum titre at $42 \mathrm{dpv}$ [14]. A drastic fall of antibody titre was observed in Group A at 180 dpv as none of the animals showed protective antibody titre. The probable reason behind not maintaining the duration of immunity up to 6 months after primary vaccination might be due to catabolism of antibodies and clearance of immunogen from host immune system. In contrast, the higher percentage of protected animal in Group B and C might be due to booster vaccination at $28 \mathrm{dpv}$. Therefore, the present study indicated that a booster vaccination is essential after $28 \mathrm{dpv}$ to keep the animals protected. Vaccination with modified live CSFV also elicited increased antibody titre after booster vaccination in pigs [15]. Moreover, a sharp rise of the protective antibody titre was noticed in all the vaccinated groups at $194 \mathrm{dpv}$ following revaccination at $180 \mathrm{dpv}$. In the present study, $194 \mathrm{dpv}$ onwards, the percentages of animals showing protective antibody 
titres were 100 in all the vaccinated groups. High level of protective antibody titres in all the CSF vaccinated groups might be due to the anamnesis antibody response of booster vaccination.

In the present study (Table-2) percentage of the herd indicates the percentage of animal possessing antibody titre $\log _{10} 1.50$ against CSFV. Further, MDA was detected in the piglets born from vaccinated sows till 42 days of age (weaning period). In the present study, the percentage of animal possessing $\log _{10} 1.50$ MDA level declined sharply (from $83.33 \%$ to $16.67 \%$ in Group B and $100 \%$ to $66.66 \%$ in Group C) on 42 days as compared to 21 days of age. From the estimation of antibody titre in piglets at 21 and 42 days of their age, it was observed that piglets born from immune sows receiving CSF vaccine during 1 month of pregnancy had a high level of passive antibody titre in comparison to piglets born from non-immune sows. The high antibody titre in piglets of Group C might be due to higher antibody level of their mothers which was subsequently transferred to their offsprings. It is assumed that passive immunity is primarily dependent on the antibody titre of the mother and on the amount of colostrums ingested by newborn piglets [16]. It is reported that newborn piglets carried MDA at $1^{\text {st }}$ week and it persisted in most of them till $7^{\text {th }}$ weeks of their age when their mothers were vaccinated against CSFV at 90 days after conceptions [17].

\section{Conclusion}

CSF causes major losses in pig farming, with various degrees of disease severity. Lapinised vaccines against CSFV are used routinely in endemic countries. However, despite intensive vaccination programs in endemic areas, CSF has not been eradicated. The present study was undertaken to establish an effective vaccination schedule for CSF on the basis of humoral immune responses in pigs vaccinated with cell culture adapted CSF vaccine. Based on the evaluation of humoral immune response of vaccinated pigs and MDA titre in piglets born from immunized sows, it may be concluded that the more effective vaccination schedule for prevention of the disease with cell culture adapted CSF vaccine is primary vaccination at 2 months of age followed by booster vaccination at 28 and $180 \mathrm{dpv}$ and at 1 month of gestation.

\section{Authors' Contributions}

The present study was a part of MKN's original research work during Ph.D. thesis program. DKS, $\mathrm{BCD}$ and SS had designed the plan of work. MKN and DK carried out the experiment in the farm. MKN, DKS, PD and PR carried out the laboratory work. MKN, PD, JBD and GM analyzed the results. All the authors read and approved the final manuscript.

\section{Acknowledgments}

Thanks are due to ICAR-National Fellow Project and ICAR-AICRP/Mega Seed Project on Pig, College of Veterinary Science, Assam Agricultural University, Khanapara for support during this study. The authors are thankful to Director of Research (Vety), College of Veterinary Science, Assam Agricultural University, Khanapara for providing necessary facilities for the present study.

\section{Competing Interests}

The authors declare that they have no competing interests.

\section{References}

1. Kumar, H., Mahajan, V., Sharma, S., Alka Singh, R., Arora, A.K., Banga, H.S., Verma, S., Kaur, K., Meenakshi, P. and Sandhu, K.S. (2007) Concurrent pastuerellosis and classical swine fever in Indian pigs. J. Swine Health Prod., 15(5): 279-283.

2. Chakarborty, S., Veeregoda, B.M., Naik, B.M.C., Rathnamma, D., Isloor, S., Venkatesha, M.D., Leena, G., Veeresh, H. and Patil, S.S. (2011) Molecular characterization and genogrouping of classical swine fever virus isolated from field outbreaks. Indian J. Anim. Sci., 81(8): 803-806.

3. Sarma, D.K., Mishra, N., Vilcek, S., Rajkumar, K., Behera, S.P., Nema, R.K., Dubey, P. and Dubey, S.C. (2011) Phylogenetic analysis of recent classical swine fever virus (CSFV) isolates from Assam, India. Comp. Immunol. Microbiol., 34(1): 11-15.

4. Huang, Y.L., Deng, M.C., Wang, F.I., Huang, C.C. and Chang, C.Y. (2014) The challenges of classical swine fever control: Modified live and E2 subunit vaccines. Virus Res., 179: 1-11.

5. Liu, L., Xia, H., Everett, H., Sosan, O., Crooke, H., Meindl-Böhmer, A., Qiu, H.J., Moennig, V., Belák, S. and Widén, F. (2011) A generic real-time TaqMan assay for specific detection of lapinized Chinese vaccines against classical swine fever. J. Virol. Methods, 175: 170-174.

6. Sarma, D.K., Deka, P., Medhi, P. and Kalita, D. (2009) An outbreak of classical swine fever in organised pig herds in Assam. Vets. Com., 5: 49-51.

7. Kumar, P. (2013) Methods for rapid virus identification and quantification. Mater. Methods, 3: 207.

8. Sarma, D.K. and Bostami, B. (2009) Comparison of liquid phase blocking ELISA and neutralization peroxidise linked assay for antigenic characterization of classical swine fever virus isolates. Indian J. Virol., 20(1): 1-3.

9. Bett, B., Deka, R., Padmakumar, V. and Rajasekhar, M. (2012) Classical swine fever in north east India: Prevention and control measures. ILRI Policy Brief., 7: 1-3.

10. Sevik, M. and Ozturk, F.F. (2013) Cmparative evaluation of liquid-phase blocking-ELISA and solid-phase competition ELISA methods for the detection of foot-and-mouth disease type $\mathrm{O}$ and A virus. Turk. J. Vet. Anim. Sci., 37: 523-528.

11. Niedbalski, W., Fitzner, A., Paprocka, G. and Kęsy, A. (1994) Application of liquid-phase blocking sandwich ELISA (LPBE) for the detection of antibodies against foot-and mouth disease virus. Bull. Vet. Inst. Pulawy, 38: 105-114.

12. Periolo, O.H., Seki, C., Grigera, P.R., Robiolo, B., Fernendiz, G., Maradei, E., D'aloia, R. and La-Torre, J.L. (1993) Large scale use of liquid phase blocking sandwich ELISA for the evaluation of protective immunity against aphthovirus in cattle vaccinated with oil-adjuvanted vaccines in Argentina. Vaccine, 11(7): 754-760.

13. Copozzo, A.V.E., Periolo, O.H., Robiolo, B., Seki, C., Torre, J.L.L.A., Grigera, P.R. and La-Torre, J.L. (1997) Total and isotype humoral responses in cattle vaccinated and foot-and-mouth disease virus (FMDV) immunogen produced either in bovine tongue or in BHK-21 cell suspension 
cultures. Vaccine, 15: 6-7.

14. Freitas, T.R.P., Caldas, L.A., Esteves, E.G., Duarte, A.C.S. and Rebello, M.A. (2009) Classical swine fever: Humoral neutralizing antibody induced by a live attenuated vaccine. Rev. Med. Vet., 6: 314-318.

15. Park, B.K., Park, Y.H. and Seo, K.S. (2000) Relation between lymphocyte subpopulations of peripheral blood and immune responses of modified live hog cholera virus vaccine in pigs treated with an ionized alkali mineral complex. J. Vet. Sci., 1(1): 49-52.
16. Muller, T., Teuffert, J., Staubach, C., Selhorst, T. and Depner, K.R. (2005) Long term studies on maternal immunity for Aujeszky's disease and classical swine fever in wild boar piglets. J. Vet. Med. B., 52(10): 432-436.

17. Portilla, J.K., Manchego, S.A., Rivera, G.H., Araínga, R.M. and Ramírez, V.M. (2009) Maternal antibody persistence against the classical swine fever virus in piglets born from vaccinated sows in farms with different vaccination strategies. Rev. Invest. Vet. Perú. (RIVEP)., 20(2): 320-326.

\section{$* * * * * * * *$}

